\title{
New nurses' Perceptions of Their Experiences During Their First Year of Practice in Oncology Setting
}

\author{
Fadi. F. FAWARIS 18 (D) $\triangle$, Khawla Ammar ${ }^{2} 8$ (D), Mohammad Farhan ${ }^{3} 8$ (D), Sara Nour ${ }^{4} 8$ (D) and Rawan \\ Atmah 58 (D) \\ ${ }^{1} \mathrm{MSN}-\mathrm{PMH}, \mathrm{RN}$, Clinical Nurse Educator at King Hussein Cancer Center, Amman, Jordan \\ ${ }^{2}$ Head-Survey Research Unit, King Hussein Cancer Center Amman, Jordan \\ ${ }^{3} \mathrm{MSN}, \mathrm{RN}$, Clinical Nurse Educator, King Hussein Cancer Centre, Amman, Jordan \\ ${ }^{45}$ MSN, RN Direct Care Nurse, King Hussein Cancer Center, Amman, Jordan \\ $\triangle$ Corresponding Author: Fadi. F. FAWARIS, E-mail: Fadi862005@yahoo.com
}

\section{ARTICLE INFORMATION ABSTRACT}

Received: February 08, 2021

Accepted: April 14, 2021

Volume: 2

Issue: 1

DOI: $10.32996 /$ jmhs.2021.2.1.1

\section{KEYWORDS}

New graduates nurses, New Oncology Nurses, Transition, Experience, Satisfaction
Background: A newly graduated nurses usually shows uneasiness in communication and dealing with clinical situations. The preceptorship program was created to develop new nurses' competencies. As well as many institutions helped their new nurses by designing a special program to ensure a smooth transition into manpower, the new graduate nurses program help them to acquire competencies which are necessary to practice the job. Aim: this study aimed to identify the nurses' satisfaction and perception, explore the relationship between nurse experience and nurse satisfaction and measure the relationship between nurse experience and their perceptions toward support, organizing and prioritizing, communication/leadership, and professional satisfaction during the first year of practice in the oncology setting

Method: A cross-sectional descriptive design was used. The participants consisted of all nurses hired by the hospital from April 2018 to April 2019. Results: A total of 101 new graduates, aged 21 to $40(m=24.02, S D=2.788)$, responded to the survey (response rate 57\%). Overall, the length of the preceptorship programs varies, and it was ranged from 8 to 12 weeks and from 4 to 6 weeks for new graduates who had completed the internship in the hospital; the respondents reported a feeling of confidence and comfort when they were asked to share their experience, $69.3 \%$ of respondents had chosen the workload (e.g. organizing, prioritizing, feeling overwhelmed, ratios, patient acuity) considering it the most difficult transition experience. The study showed significant positive relationships between nurses' experience and their satisfaction (salary, benefits package, Opportunity to work straight days, and Opportunities for career advancement) and significant negative relationships between nurses' experience and their perception of support factors and professional Satisfaction factor. Conclusion: the results of this study reflect the challenges experienced with fear, stress, and confidence during first year of practice. Considering the new graduate nurse's experience and voice will reflect positively on practice.

\section{Introduction}

Transitioning the nurses from school to new graduate nurses and experienced nurses can be conflicting (Randall, Furze, \& Thunhurst, 2015). Many models of care were applied for novice nurses in order to develop competent and safe practice(Blegen et al., 2015; Hussein, Everett, Ramjan, Hu, \& Salamonson, 2017; Kamolo, Vernon, Head, \& Toffoli, 2017; Katherine ValdezDelgado \& Barker, n.d.; Parker, Giles, Lantry, \& Mcmillan, n.d.; Phillips, Kenny, Esterman, \& Smith, 2014). Many studies showed that nurses in the first year of practice are not prepared well for the workplace; the workplace dynamics and workflow daunting

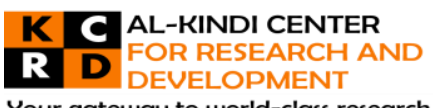

Your gateway to world-class research

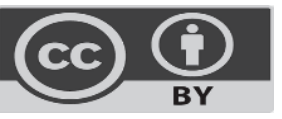

Published by Al-Kindi Center for Research and Development, United Kingdom. Copyright (c) the author(s). This open access article is distributed under a Creative Commons Attribution (CC-BY) 4.0 license 
(Valizadeh, Borimnejad, Rahmani, Gholizadeh, \& Shahbazi, 2016)(Candela \& Bowles, 2008). Many researchers mark the points that the new graduate nurses (NGNs) require at least 1 year to be confident and comfortable(Parker et al., n.d.). As well as many institutions helped their new nurses by designing a special program to ensure a smooth transition into manpower, the new graduate nurses program helps them acquire competencies necessary to practice the job. Many research pointed up to integrate the transition model in healthcare policy, as well as implementing models and program will be helpful for new nurses to over jump the obstacles. For example, Phillips (2014) applied the Competency Outcomes and Performance Assessment Model (COPA) as a theoretical framework for new nurses by providing competencies assessments checklist and monitoring the outcomes; he found that the COPA model is an effective framework for nurses who are new and provide them practical guideline(Lenburg, Abdur-Rahman, \& Klein, 2009; Phillips et al., 2014)

Jones-Bell and her colleagues highlighted the importance of beginning nurse residency and transitioning to practice program in all nursing settings (Jones-Bell, Halford-Cook, \& Parker, 2018). Furthermore, there are many studies stated that the quality of the clinical orientation, level of nursing leadership empowerment, availability of the clinical instructor and preceptors and clinical mentoring are contributed to enhancing the new graduate nurse transition and experiences (Cho, Spence Laschinger, \& Wong, 2013; Halfer, 2015; Naholi, Nosek, \& Somayaji, 2015).

\subsection{Residency and transition to practice program}

Implementing transition to practice program (nurse residency) bridges the gap between nurse's expectations and reality (JonesBell et al., 2018). The Institute of Medicine had been suggested to advance the nurse's transition in order to become more comfortable (Fink, Krugman, Casey, \& Goode, 2008). Valizadeh and his colleagues conducted a qualitative study to understand graduate nurse transition difficulties better and determine the improving graduate nurse support and integration. The findings of this study identified the following five transition difficulties theme: orientation issues, workload, lack of confidence, fears, and role changes. Also, they found four improving graduate nurse support and integration theme: increased support, improved orientation, work environment and socialization. On the other hand, the respondents stated that the nurse manager support is one of the best ways to facilitate the transition(Valizadeh et al., 2016). Similarly, Bratt and Felzer (2011) found that participants who had completed the nurse residency program had shown significant improvement in job satisfaction, clinical decisionmaking, and lower stress levels (Bratt \& Felzer, 2011).

\subsection{Theoretical Framework}

The Dreyfus model was modified by Benner (2001) to describe skill acquisition in nursing and to explore how the knowledge is gained. Dreyfus model consists of five stages; Stage one is a novice, the learner has no experience base, characterized with lack of confidence to demonstrate safe practice, and following plans and rules (Lyon, 2015). In the second stage, the knowledge is developing because the learner has had dynamic experience rather than practical in the actual situation; nevertheless, there is still a need for occasional support. This stage is known as an advanced beginner (Lyon, 2015). The third stage is competent; the learner can independently perform multitasks within an appropriate time frame, understand more, and manage emergencies. The fourth stage is Proficient; the learner becomes aware of situations in a holistic way rather than as a task. Finally, in the fifth stage, which is the expert stage, the learner becomes highly proficient can analyze while dealing with situations; the learner will no longer depend on rules or guidelines (Khan \& Ramachandran, 2012; Lyon, 2015).

\subsection{Significance of the Study}

A newly graduated nurse usually shows uneasiness in communication and dealing with clinical situations. The preceptorship program was created to develop new nurses' competencies; unfortunately, some of the core information is missed. Many researchers established standard transition-to practice program for new graduate nurses. Thus, the residency program will improve the clinical orientation, job satisfaction, clinical mentoring and retention rate (Crimlisk et al., 2017; Halfer, 2015; Parker, Giles, Lantry, \& Mcmillan, 2014; Phillips et al., 2014)

\subsection{Aim}

a. To identify the nurses' satisfaction and perception during the first year of practice in an oncology setting.

b. To measure the relationship between nurse experience and nurse satisfaction during the first year of practice in the oncology setting.

c. To measure the relationship between nurse experience and their perceptions toward support, organizing and prioritizing, communication/leadership, and professional satisfaction during the first year of practice in the oncology setting. 


\section{Method}

\subsection{Study Design}

A cross-sectional descriptive design using survey questionnaires was conducted to explore new nurses' perceptions of their experiences during their first year of practice. The Nurses who were eligible for participation was hired from April 2018 to April 2019, And who able to sign the informed consent document then asked to fill both demographic data and the revised CaseyFink graduate nurse experience survey.

This study took place at a Not-profit specialized oncology center in Jordan. It consists of 352 beds provides specialized and unique care of oncology and cancer services. This center provides psychological, social worker and transportation services for patients. More than 1000 nurses are working in this center, and the participants consisted of all nurses hired by the hospital from April 2018 to April 2019.

Inclusion criteria were all newly hired nurses for the medical, surgical, pediatric, critical care, operating room, Palliative care, and emergency unit from April 2018 to April 2019. The exclusion criteria included newly hired nurses with experience from another hospital. The sample was obtained from the hospital's entire newly hired nurses from April 2018 to April 2019. The response rate was $\% 57$.

\subsection{Instruments}

All participants completed the version of the revised Casey-Fink graduate nurse experience survey. The survey was created in 1999 and revised in 2002 and again in 2006 (Casey and Fink 2009). The instrument contains 5 category: demographic information; the respondents asked to choose top of 3 skills and procedure from list of 18 skills and procedure that were uncomfortable while performing ${ }_{i}$ comfort and confidence category which consist of 24 questions with Likert scale response from 1 = strongly disagree to 4 = strongly agree; job satisfaction category consists of 9 questions with 5-point Likert scale ranging from 1 = very dissatisfied to 5 = very satisfied; and 4 questions examined work environment and difficulties in the transition phase. Demographic data questions contain age, gender, area of employment, date of hire, number of preceptors during the orientation, schedule work pattern, and unit orientation length-additional questions with yes or No answer to address new nurses' stressors.

\subsection{Ethical consideration}

Ethical approval from the institutional review board (IRB) was obtained to conduct the study. Participation is voluntary and all respondents have the right to refuse or withdraw from the study at any time without any consequences. In order, all participants' information remained confidential. The completed questionnaires kept in a secured place in the PI office and restrict access to these documents except the primary investigator. Participants who agreed to participate in the study were interviewed in a private room to fill the questionnaires.

\section{Result}

\subsection{Demographics}

A total of 101 new graduate nurses completed the survey; the participants' age ranged between 21 and 40 years $(\mathrm{m}=24.02, \mathrm{SD}=$ 2.788). The majority of the participants were male $(65.66 \%, n=66)$; all of the participants had a bachelor of science in nursing. In addition, most of the participants (86\%) had one preceptor during their orientation program. The graduate nurses trained in several clinical areas: critical care, pediatric service, medical/surgical, ER, and speciality services, such as palliative and hospice care unit, BMT, home care and wound team (Table 1).

The preceptorship programs' length varies and ranges from 8 to 12 weeks and from 4 to 6 weeks for new graduates who had completed the internship in the hospital.

The respondents were asked to select the top 3 skills and procedures from the list of 18 items that they were uncomfortable while performing, $34.6 \%$ were uncomfortable with acute spinal cord injury care, $30.6 \%$ of respondents were

uncomfortable with assisting with Bone marrow aspiration and biopsy, and $25.7 \%$ of respondents were uncomfortable with Chemotherapy administration. 


\section{Table 1 : Sample characteristics}

\begin{tabular}{|c|c|c|c|}
\hline Characteristics & Domain & Frequency & Percentage \\
\hline \multirow{2}{*}{ Gender } & Male & 66 & $66 \%$ \\
\hline & Female & 35 & $34 \%$ \\
\hline \multirow{2}{*}{ Age } & Mean & 24.02 & \\
\hline & SD & 2.788 & \\
\hline \multirow{3}{*}{ Number of preceptor } & 1 & 86 & $86 \%$ \\
\hline & 2 & 8 & $8.2 \%$ \\
\hline & More than 2 & 7 & $5.8 \%$ \\
\hline \multirow{2}{*}{ scheduled work pattern } & Rotating days/nights & 90 & $89 \%$ \\
\hline & Straight days/ fixed shifts & 11 & $11 \%$ \\
\hline \multirow{2}{*}{$\begin{array}{l}\text { Length of unit orientation } \\
\text { programs different }\end{array}$} & 8 weeks & 62 & $61 \%$ \\
\hline & $9-12$ weeks & 24 & $24 \%$ \\
\hline $\begin{array}{l}\text { Length of unit orientation } \\
\text { programs/ completed the } \\
\text { internship in the hospital }\end{array}$ & 4-6 weeks & 15 & $15 \%$ \\
\hline
\end{tabular}

\section{Job Satisfaction}

The 101 respondents were queried about job satisfaction and it was measured by 7 items about salary, vacation, benefits package, and work schedule, opportunity of career advancement, and encouragement and feedback. The results showed $56 \%$ were satisfied with their salary, $40 \%$ were satisfied with their vacations, $41 \%$ were satisfied with their benefits package i.e. bonus, cola, medical insurance, etc. $30.6 \%$ were satisfied with their work schedule, $46 \%$ reported they were satisfied with opportunity of career advancement and $35 \%$ of respondents were satisfied with the amount of encouragement and feedback from their preceptors, managers and peers. The total job satisfaction mean score was $\left(M=41.4 \_S D=8.87\right)$.

\subsubsection{Transition to practice difficulties}

In response to the question," What difficulties, if any, are you currently experiencing with the transition from the "student" role to the "RN" role?" $69.3 \%$ of respondents had chosen the workload (e.g. organizing, prioritizing, feeling overwhelmed, ratios, patient acuity) considering it the most transition difficult experience, and $27.7 \%$ of respondents had chosen the fear, $21.7 \%$ had chosen the role expectations (e.g. autonomy, more responsibility, being a preceptor or in charge), $18.8 \%$ had chosen lack of confidence (e.g. MD/PT communication skills, delegation, knowledge deficit, critical thinking) and $16.8 \%$ chose orientation issues (e.g. unit familiarization, learning technology, relationship with multiple preceptors, information overload) (table 2).

In order to measure how they are supported in the unit, they asked to answer the question, "What could be done to help you feel more supported or integrated into the unit?" $52 \%$ of the respondents stated that increased support (e.g. manager, RN, and educator feedback and support, mentorship) helped them ease their integration with the unit's team. On the other hand, the respondents were asked about the most and least satisfying aspects of the work environment. The result showed that ongoing learning $42 \%$, peer support $35 \%$, and $35 \%$ positive feedback from the patients and families were most satisfying. In contrast, the least satisfying was $49 \%$ system (e.g. outdated facilities and equipment, small workspace, charting, paperwork, and $34 \%$ nursing work environment (e.g. unrealistic ratios, tough schedule, the futility of care).

\subsubsection{Work stress}

There were 6 statement related to new graduate nurse level of stress while working as RN which include, Finances, Childcare, Student loans, Living situation, Personal relationships, Job performance, the result showed that $29 \%$ of respondents stated that the job performance is the most cause of stress, $26 \%$ finance status, and $21 \%$ Personal relationships. 


\subsubsection{Confidence and comfort}

The respondents reported a feeling of confidence and comfort when they asked to share their experience, $88 \%$ of new graduate nurse feel confident communicating with physician, $95 \%$ feel that the staff available during new situations and procedure, $91 \%$ stated that the preceptors provide encouragement and feedback, $65 \%$ feeling less comfort for prioritizing patient care needs, $42 \%$ feel overwhelmed regarding patient care responsibilities and workload, and $63 \%$ stated that might cause harm to the patient due to lack of knowledge and experience.

Table 2 : Nurse Satisfaction and Perception

\begin{tabular}{|c|c|c|}
\hline Domains & Mean & SD \\
\hline Total Satisfaction & 41.4 & 8.87 \\
\hline Salary & 2.24 & 1.036 \\
\hline Vacation & 3.39 & 1.109 \\
\hline Hours that you work & 2.83 & 1.167 \\
\hline Weekends off per month & 2.96 & 1.121 \\
\hline A mount of responsibility & 3.46 & 0.997 \\
\hline Benefits package & 3.30 & 1.047 \\
\hline Opportunities for career advancement & 3.50 & 1.067 \\
\hline Encouragement and feedback & 3.46 & 0.997 \\
\hline Opportunity to work straight days & 3.15 & 1.143 \\
\hline \multicolumn{3}{|l|}{ Total Perception } \\
\hline Support factors & 3.14 & 0.08 \\
\hline Organizing and prioritizing factor, & 2.82 & 0.11 \\
\hline Communication/leadership factor & 3.08 & 0.11 \\
\hline Professional Satisfaction factor & 3.06 & 0.09 \\
\hline $\begin{array}{l}\text { What difficulties, if any, are you currently experiencing with } \\
\text { the transition from the "student" role to the "RN" role }\end{array}$ & Frequency & Percentage \\
\hline Role expectations & 22 & $21.7 \%$ \\
\hline Lack of confidence & 19 & $18.8 \%$ \\
\hline Workload & 70 & $69.3 \%$ \\
\hline Fears & 28 & $27.7 \%$ \\
\hline Orientation issues & 17 & $16.8 \%$ \\
\hline
\end{tabular}




\subsection{Relationship between Nurse Experience and Their Satisfaction}

Table 3 presented the relationship between nurse experience and their satisfaction. The results indicated that there were significant positive relationships between nurse experience and their satisfaction with salary $(r=.292, P=.049)$, benefits package $(r=.291, P=.049)$, Opportunities for career advancement $(r=327, P=.041)$, and Opportunity to work straight days $(r=326$, $P=$ $.041)$.

Table 3: Relationship between Nurse Experiences and Nurse Satisfaction

\begin{tabular}{|c|c|c|}
\hline & & Nurse Experience \\
\hline \multirow[t]{2}{*}{ Salary } & Pearson Correlation & .292 \\
\hline & Sig. (2-tailed) & $.049 *$ \\
\hline \multirow[t]{2}{*}{ Vacation (Annual Leave) } & Pearson Correlation & .055 \\
\hline & Sig. (2-tailed) & .588 \\
\hline \multirow[t]{2}{*}{ Hours that you work } & Pearson Correlation & .046 \\
\hline & Sig. (2-tailed) & .656 \\
\hline \multirow[t]{2}{*}{ Weekends off per month } & Pearson Correlation & -.103 \\
\hline & Sig. (2-tailed) & .314 \\
\hline \multirow[t]{2}{*}{ A mount of responsibility } & Pearson Correlation & .312 \\
\hline & Sig. (2-tailed) & .046 \\
\hline \multirow[t]{2}{*}{ Benefits package } & Pearson Correlation & .291 \\
\hline & Sig. (2-tailed) & $.049 *$ \\
\hline \multirow[t]{2}{*}{ Opportunities for career advancement } & Pearson Correlation & .327 \\
\hline & Sig. (2-tailed) & $041^{*}$ \\
\hline \multirow[t]{2}{*}{ Encouragement and feedback } & Pearson Correlation & -.010 \\
\hline & Sig. (2-tailed) & .922 \\
\hline \multirow[t]{2}{*}{ Opportunity to work straight days } & Pearson Correlation & .326 \\
\hline & Sig. (2-tailed) & $.041^{*}$ \\
\hline
\end{tabular}

\subsection{Relationship between Nurse Experience and Their Perception}

Table 4 presented the relationship between nurse experience and their perception, and the results indicated significant negative relationships between nurse experience and their perception of support factors $(r=-.272, P=.048)$, and professional Satisfaction factor $(r=-.346, P=.01)$. The respondents were queried about the level of support which was measured by 9 statements include (helped from other RNs, preceptor encouragement and feedback, staff availability, supports from the nurses at the unit, the opportunity to practice skills and procedure more than once, job realistic, positive role model, helping to be confident in practice, and manager encouragement and feedback) and professional satisfaction which was measured by 3 statement include (supported by family/friend, satisfied with nursing speciality, and the work is exciting and challenging).

Table 4: Relationship between Nurse Experiences and Their Perception

\begin{tabular}{|l|l|r|}
\hline \multicolumn{2}{|l|}{} & Nurse Experience \\
\hline \multirow{2}{*}{ Support Factors } & Pearson Correlation & -.272 \\
\cline { 2 - 3 } & Sig. (2-tailed) & $.048^{\star}$ \\
\hline \multirow{2}{*}{ Organizing and Prioritizing Factor } & Pearson Correlation & .122 \\
\cline { 2 - 3 } Communication/leadership factor & Sig. (2-tailed) & .148 \\
\hline & Pearson Correlation & .155 \\
\cline { 2 - 3 } & Sig. (2-tailed) & .133 \\
\hline
\end{tabular}




\begin{tabular}{|l|l|c|}
\hline \multirow{2}{*}{ Professional Satisfaction factor } & Pearson Correlation & -.346 \\
\cline { 2 - 3 } & Sig. (2-tailed) & $.01^{\star}$ \\
\hline
\end{tabular}

\section{Discussion}

This study aimed to explore the new nurses' perception during their first year of practice. In order to accomplish this aim, three objectives were specified: (a) to identify the nurse satisfaction and perception during the first year of practice in an oncology setting, (b) To measure the relationship between nurse experience and nurse during the first year of practice in an oncology setting, (c) To measure the relationship between nurse experience and their perceptions toward support, organizing and prioritizing, communication/leadership, and professional satisfaction during the first year of practice in an oncology setting. According to this study, it was clear that new nurses who had 1 preceptor were more confident and comfortable than those who was had more than 1 preceptor. This is consistent with a literature review that explores the preceptorship experience (Luhanga, Billay, Grundy, Myrick, \& Yonge, 2010)(Kamolo, Vernon, Head, \& Toffoli, 2017).

The organisation and nursing support at the administrative level was positively associated with new nurses' satisfaction. Support from both nurse manager and peers consist of feedback and guidance related to the work setting. This result is consistent with a qualitative study that explored the workplace empowerment, work engagement and organizational commitment for the new graduate nurses, (Cho et al., 2013; Ning, Zhong, Libo, \& Qiujie, 2009) and other many studies showed that nurses feel more comfort, positive feeling, high satisfaction and more sense of control. (Goss, 2015; Li, Kuo, Huang, Lo, \& Wang, 2013; Peters, Poutsma, Heijden, B. Bakker, \& De Bruijn, 2014).

The result revealed that most new nurses stated that the work stress and workload include organizing and prioritizing patient care, feeling overwhelmed, Nurse-to-patient ratios, and patient acuity are distressing difficulties. These findings are consistent with the literature. Hussein and his colleagues (2017) reported that the new nurses felt that the workload was unrealistic due to high patient acuity and high nurse to patient ratios (Hussein, Everett, Ramjan, Hu, \& Salamonson, 2017). Parker et al. (2014), in their mixed-method cross-sectional study, found that the majority of respondents describe their work as emotionally challenging, heavy workload and high-stress work area.(Parker, Giles, Lantry, \& Mcmillan, 2014). The orientation program for new nurses is essential to ease their transition to practice (Crimlisk et al., 2017; Piccinini, Hudlun, Branam, \& Moore, 2018). The comprehensive orientation, continuous support from clinical education, support from the unit manager, and formally introduction to the unit staff were identified as significant factors as they promoted new nurses' transition.

Our finding showed that there were significant positive relationships between nurse experience and their satisfaction (salary, benefits package, opportunity to work straight days, and Opportunities for career advancement), which is consistent with studies showed that the nurses' satisfaction increase over time as a result of more sense of control. Furthermore, the study showed significant negative relationships between nurse experience and their perception of support factors and professional Satisfaction factor. It is unclear if the low satisfaction of support and professional result from their expectation or result from other factors such as workload, ward educators or preceptors, staff shortage, and unrealistic expectations.

\section{Conclusion}

It is marked that the success of new graduate nurses' transition is vital to confirm a safe and competent. Considerating the new graduate nurse's experience and voice will positively reflect practice.

\section{Study Limitations}

This study used a self-reported, which may lead to bias. The sample in this study only from one specialized hospital limits the ability to generalize the finding to other settings.

\section{References}

[1] Bratt, M. M., \& Felzer, H. M. (2011). Perceptions of Professional Practice and Work Environment of New Graduates in a Nurse Residency Program. The Journal of Continuing Education in Nursing, 42(12), 559-568. https://doi.org/10.3928/00220124-20110516-03

[2] Candela, L., \& Bowles, C. (2008). RECENT RN GRADUATE PERCEPTIONS of Educational Preparation. Nursing Education Perspectives, 29(5).

[3] Cho, J., Spence Laschinger, H., \& Wong, C. (2013). Workplace Empowerment, Work Engagement and Organizational Commitment of New Graduate Nurses. Nursing Leadership, 19(3), 43-60. https://doi.org/10.12927/cjnl.2006.18368

[4] Crimlisk, J. T., Grande, M. M., Krisciunas, G. P., Costello, K. V, Fernandes, E. G., \& Griffin, M. (2017). Nurse residency program designed for a large cohort of new graduate nurses: implementation and outcomes. MedSurg Nursing, 26(2), 83-104. Retrieved from http://cmpsezproxy.mnu.edu:2057/login.aspx?direct=true\&db=rzh\&AN=122315808\&site=eds-live

[5] Fink, R., Krugman, M., Casey, K., \& Goode, C. (2008). The Graduate Nurse Experience. The Journal of Nursing Administration, 38(7/8), 341348. https://doi.org/10.1097/01.nna.0000323943.82016.48

[6] Goss, C. (2015). Systematic review building a preceptor support system. Journal for Nurses in Professional, 37(1). Retrieved from https://journals.Iww.com/jnsdonline/Fulltext/2015/01000/Systematic_Review_Building_a_Preceptor_Support.18.aspx

[7] Halfer, D. (2015). A magnetic strategy for new graduate nurses. Nursing Economic, 25(1), 6-11. Retrieved from 
http://www.ncbi.nlm.nih.gov/pubmed/17402672

[8] Hussein, R., Everett, B., Ramjan, L. M., Hu, W., \& Salamonson, Y. (2017). New graduate nurses' experiences in a clinical specialty: A follow up study of newcomer perceptions of transitional support. BMC Nursing, 16(1). https://doi.org/10.1186/s12912-017-0236-0

[9] Jones-Bell, L. J., Halford-Cook, C., \& Parker, N. (2018). Transition to Practice - Part 3: Implementing an Ambulatory Care Registered Nurse Residency Program: RN Residency and Transition to Professional Practice Programs in Ambulatory Care - Challenges, Successes, and Recommendations. Nursing Economic, 36(1), 35-45. Retrieved from http://search.ebscohost.com/login.aspx?direct=true\&db=ccm\&AN=128049878\&site=ehost-live

[10] Kamolo, E., Vernon, R., Head, A., \& Toffoli, L. (2017). A Critical Review of Preceptor Development for Nurses Working with Undergraduate Nursing Students. International Journal of Caring Sciences, 10, 1089. Retrieved from www.internationaljournalofcaringsciences.org

[11] Khan, K., \& Ramachandran, S. (2012). Conceptual framework for performance assessment: Competency, competence and performance in the context of assessments in healthcare - Deciphering the terminology. Medical Teacher, 34(11), 920-928. https://doi.org/10.3109/0142159X.2012.722707

[12] Lenburg, C. B., Abdur-Rahman, V. Z., \& Klein, C. J. (2009). Implementing the COPA Model in Nursing Education and Practice Settings, $0-7$.

[13] Li, I.-C., Kuo, H.-T., Huang, H.-C., Lo, H.-L., \& Wang, H.-C. (2013). The mediating effects of structural empowerment on job satisfaction for nurses in long-term care facilities. Journal of Nursing Management, (21), 440-448. https://doi.org/10.1111/j.1365-2834.2012.01396.x

[14] Luhanga, F. L., Billay, D., Grundy, Q., Myrick, F., \& Yonge, O. (2010). The one-to-one relationship: Is it really key to an effective preceptorship experience? A review of the literature. International Journal of Nursing Education Scholarship, 7(1). https://doi.org/10.2202/1548-923X.2012

[15] Lyon, L. J. (2015). Development of teaching expertise viewed through the Dreyfus model of skill acquisition. Journal of the Scholarship of Teaching and Learning, 15(1), 88-105. https://doi.org/10.14434/josotl.v15i1.12866

[16] Naholi, R. M., Nosek, C. L., \& Somayaji, D. (2015). Stress among new oncology nurses. Clinical Journal of Oncology Nursing, 19(1), $115-117$. https://doi.org/10.1188/15.CJON.115-117

[17] Ning, S., Zhong, H., Libo, W., \& Qiujie, L. (2009). The impact of nurse empowerment on job satisfaction. The Authors. Journal Compilation Ó, 65(12), 2642-2648. https://doi.org/10.1111/j.1365-2648.2009.05133.x

[18] Parker, V., Giles, M., Lantry, G., \& Mcmillan, M. (2014). New graduate nurses' experiences in their first year of practice. Nurse Education Today, 34(1), 150-156. https://doi.org/10.1016/j.nedt.2012.07.003

[19] PETERS, P., POUTSMA, E., HEIJDEN, B., B. BAKKER, A., \& DE BRUIJN, B. (2014). ENJOYING NEW WAYS TO WORK: AN HRM-PROCESS APPROACH TO STUDY FLOW. Human Resource Management, 53(2), 271-290. https://doi.org/10.1002/hrm.21588

[20] Phillips, J. (2014). Helping community-based students on a final consolidation placement make the transition to registered practice. British Journal of Community Nursing, 19(7), 352-356. https://doi.org/10.12968/bjcn.2014.19.7.352

[21] Piccinini, C. J., Hudlun, N., Branam, K., \& Moore, J. M. (2018). The Effects of Preceptor Training on New Graduate Registered Nurse Transition Experiences and Organizational Outcomes. The Journal of Continuing Education in Nursing, 49(5). https://doi.org/10.3928/00220124-20180417-06

[22] Randall, S., Furze, G., \& Thunhurst, C. (2015). 'I can't walk away': understanding the complexities in embedding a new nurse role. British Journal of Community Nursing, 20(11), 543-550. https://doi.org/10.12968/bjcn.2015.20.11.543

[23] Spector, N., Blegen, M. A., Silvestre, J., Barnsteiner, J., Lynn, M. R., Ulrich, B., ... Alexander, M. (2015). Transition to Practice Study in Hospital Settings. Journal of Nursing Regulation, 5(4), 24-38. https://doi.org/10.1016/S2155-8256(15)30031-4 